\title{
Cytokines secreted by human Wharton's jelly stem cells inhibit the proliferation of ovarian cancer (OVCAR3) cells in vitro
}

\author{
GAUTHAMAN KALAMEGAM ${ }^{1,2}$, KHALID HUSSEIN WALI SAIT ${ }^{3}$, NISREEN ANFINAN ${ }^{3}$, \\ ROAA KADAM ${ }^{1}$, FARID AHMED $^{1}$, MAHMOOD RASOOL $^{1}$, MOHAMMAD IMRAN NASEER $^{1}$, \\ PETER NATESAN PUSHPARAJ $^{1}$ and MOHAMMED AL-QAHTANI ${ }^{1}$ \\ ${ }^{1}$ Center of Excellence in Genomic Medicine Research (CEGMR), King Abdulaziz University, \\ Jeddah 21589, Kingdom of Saudi Arabia; ${ }^{2}$ Faculty of Medicine, AIMST University, Bedong, Kedah 08100, Malaysia; \\ ${ }^{3}$ Department of Obstetrics and Gynaecology, Faculty of Medicine, King Abdulaziz University Hospital, \\ Jeddah 22252, Kingdom of Saudi Arabia
}

Received October 4, 2018; Accepted January 23, 2019

DOI: $10.3892 /$ ol.2019.10094

\begin{abstract}
Cytokines enhance tumour cell recognition via cytotoxic effector cells and are therefore effectively used in cancer immunotherapy. Mesenchymal stem cells have efficient homing potential and have been used to target and inhibit various types of cancer mediated by the release of soluble/bioactive factors. Initial evaluation of the human Wharton's jelly stem cell conditioned medium (hWJSC-CM) and cell lysate (hWJSC-CL) against an ovarian cancer cell line (OVCAR3) demonstrated their inhibitory effect in vitro. The secreted cytokine profile was then studied to understand whether the OVCAR3 inhibitory effect was mediated by the cytokines. Expression of cytokines in OVCAR3 following $48 \mathrm{~h}$ treatment with hWJSC extracts, namely the hWJSC-CM (50\%) and hWJSC-CL $(10 \mu \mathrm{g} / \mathrm{ml})$, was evaluated using multiplex cytokine assay. Paclitaxel $(5 \mathrm{nM})$ was used as a positive control. Cytokines tumour necrosis factor $\alpha$, interleukin (IL)-4, IL-6, IL-8, IL-10, IL-13, IL-17, IL-1 $\beta$ and granulocyte colony-stimulating factor, reported to be involved in tumour growth, invasion and migration, were significantly decreased. Cytokines with antitumour effects, namely IL-1 receptor antagonist (IL-1RA), IL-2, IL-2 receptor, IL-5, IL-7, IL-12, IL-15, interferon (IFN)- $\alpha$ and IFN- $\gamma$, were mildly increased or decreased. Only the increases in IL-1RA (with paclitaxel, hWJSC-CM and hWJSC-CL) and granulocyte-macrophage colony-stimulating factor (with hWJSC-CL) were statistically significant. The chemokines monocyte chemoattractant protein 1 , macrophage inflammatory protein (MIP)-1 $\alpha$, MIP- $1 \beta$ and Regulated Upon Activation, Normally T-Expressed, and
\end{abstract}

Correspondence to: Dr Gauthaman Kalamegam, Center of Excellence in Genomic Medicine Research (CEGMR), King Abdulaziz University, Prince Majid Road, Jeddah 21589, Kingdom of Saudi Arabia E-mail:kgman@hotmail.com; kgauthaman@kau.edu.sa

Key words: stem cells, ovarian cancer, cytokines, chemokines, growth factors, cluster analysis
Secreted were significantly decreased while monokine induced by IFN- $\gamma$, IFN- $\gamma$ induced protein 10 and Eotaxin demonstrated mild decreases. The growth factors basic fibroblast growth factor, vascular endothelial growth factor and hepatocyte growth factor were significantly decreased. Heatmaps demonstrated differential fold changes in cytokines and hierarchical cluster analysis revealed 3 major and 7 minor sub-clusters of associated cytokines, chemokines and growth factors. In conclusion, the hWJSC extracts decreased the expression of oncogenic cytokines, chemokines and growth factors, which mediated the inhibition of OVCAR3 cells in vitro.

\section{Introduction}

Ovarian cancer is the fifth leading cause of cancer-associated mortality among women with $>20,000$ new cases and 14, 000 mortalities estimated in the USA in 2018 (1). Ovarian cancer has an asymptomatic onset and the majority of cases are detected in the late stages, when tumour metastasis has occurred (2). Despite the best possible treatment, the mortality rate remains high, and the 5-year overall survival rate is $<40 \%$. Early diagnosis leads to a better prognosis, with a $95 \%$ survival rate if the disease is confined to the ovary, $79 \%$ if there is adjacent tissue infiltration, and $28 \%$ if the disease is advanced (3). Industrialized nations have been reported to have higher incidence of ovarian cancer due to environmental factors. It has also been observed that the risk of developing epithelial ovarian cancer (EOC) is 1.5 -fold higher in women who have never breastfed, compared to those who have breastfed for $>18$ months. This observation is linked to the reduction in ovarian cancer incidence observed with the use of oral contraceptives $(4,5)$. Overall, $\sim 90 \%$ cases of ovarian cancer arise from the epithelium, $3 \%$ from the germ cells and $2 \%$ from the sex-cord stromal cells. EOC is histologically subdivided into serous (70\%), endometrioid (10\%), mucinous $(6 \%)$ and clear cell $(6 \%)$, differing in their genetic status and therapeutic response (6).

Despite conventional debulking surgery and the development of adjuvant chemotherapy using platinum/taxane-based drugs, no significant improvement has been noted in 
ovarian cancer prognosis. This is largely due to the emergence of multidrug resistance, predisposing the patient to relapse (7). Novel agents and molecules are currently being investigated, and, notably, mesenchymal stem cells (MSCs) and their soluble factors are reported to exhibit beneficial anticancer effects $(8,9)$. MSCs migrate to damaged tissues, sites of inflammation and tumour sites, and contribute either directly or indirectly towards restoring homeostasis (10). These cells generally have low immunogenicity and escape immune surveillance, enabling them to reach the intended site of action (11). Within the tumour environment, MSCs are reported to dynamically interact with tumour-associated cells and release soluble factors (cytokines, chemokines and growth factors) with autocrine and paracrine functions (12). However, the interaction between MSCs and tumour cells depends on a number of factors, and the overall outcome determines whether the tumour subsides or progresses.

Cytokines are low-molecular-weight glycoproteins produced by immune and non-immune cells. Functionally, these proteins are pleotropic, and the expression of receptors to various cytokines on the cell surface facilitates cell-cytokine interactions. Dysregulation of cytokines may result in disease or a pathological state, and the measurement of their levels helps monitor disease severity or therapeutic intervention (13). Research on cytokines has evolved rapidly in the last decade, contributing to molecular and immunological insights in health and disease. Cancer is a state of chronic inflammation, and signalling involving tumour progression, inhibition, metastasis or immunomodulation is partially regulated by cytokines and/or chemokines (14). A previous study has suggested that EOC is immunogenic, as indicated by the presence of tumour-reactive $\mathrm{T}$ cells in the tumour microenvironment, which is associated with higher production of IFN- $\gamma$ induced monkine and secondary lymphoid tissue chemokine contibuting to improvement in the overall survival rate (15).

Considering the beneficial effects of MSCs against cancer, and the role of cytokines in tumour inhibition and therapeutics, the in vitro effect of human Wharton's Jelly stem cell conditioned medium (hWJSC-CM) and cell lysate (hWJSC-CL) against an ovarian cancer cell line (OVCAR3) was evaluated. The two hWJSC extracts inhibited OVCAR3 cell proliferation, partly mediated by their soluble factors, leading to the decreased expression of oncogenic cytokines, chemokines and growth factors.

\section{Materials and methods}

Ethical approval. The present study was performed in accordance with the recommendations of the Bioethics Committee of the King Abdulaziz University, Jeddah, Saudi Arabia. All subjects provided written informed consent, in accordance with the Declaration of Helsinki. The protocol for the derivation and use of hWJSCs, and the commercial human ovarian cancer cell line (OVCAR3) was approved by the Bioethics Committee of the King Abdulaziz University (approval no. 33-15/KAU).

Derivation of hWJSCs. Human umbilical cord specimens $(n=5)$ were collected from patients undergoing full-term delivery at the Department of Obstetrics and Gynaecology,
King Abdulaziz University Hospital. The hWJSCs were derived as previously described $(16,17)$. Briefly, the umbilical cord was cut into $\sim 2-\mathrm{cm}$ pieces, opened lengthways, and the blood vessels were removed. The cut pieces were treated with an enzyme cocktail containing $2 \mathrm{mg} / \mathrm{ml}$ collagenase type-I, $2 \mathrm{mg} / \mathrm{ml}$ collagenase type-IV and 100 IU hyaluronidase for 30 min (Sigma-Aldrich; Merck KGaA, Darmstadt, Germany). The matrix contents were gently scraped and the medium containing the cells was centrifuged at $500 \mathrm{x} \mathrm{g}$ for $5 \mathrm{~min}$. The cell pellet was washed twice with PBS and centrifuged at $500 \mathrm{x}$ g for $5 \mathrm{~min}$ again. The resultant pellet was resuspended in hWJSC culture medium comprised of high-glucose Dulbecco's Modified Eagle's Medium (DMEM; Sigma-Aldrich; Merck KGaA) supplemented with $10 \%$ fetal bovine serum (FBS; Sigma-Aldrich; Merck KGaA), 2 mM Glutamax (Thermo Fisher Scientific, Inc., Waltham, MA, USA), 1\% non-essential amino acids (Thermo Fisher Scientific, Inc.), $16 \mathrm{ng} / \mathrm{ml}$ basic fibroblast growth factor (bFGF; Sigma-Aldrich; Merck KGaA) and $1 \%$ antibiotics $(50 \mathrm{IU} / \mathrm{ml}$ penicillin and $50 \mu \mathrm{g} / \mathrm{ml}$ streptomycin, Sigma-Aldrich; Merck KGaA), and incubated under standard culture conditions of $37^{\circ} \mathrm{C}$ in a $5 \% \mathrm{CO}_{2}$ incubator. The cultures were left undisturbed until cell growth was evident, except for gentle changes of the growth medium every $72 \mathrm{~h}$.

CD marker analysis. Cultures of hWJSCs were analyzed for expression of MSC related cluster of differentiation (CD) markers as reported earlier (18). Briefly, monolayer cultures of hWJSCs were dissociated using 0.25\% Trypsin-EDTA (Life Technologies, Carlsbad, CA, USA) for $3 \mathrm{~min}$. Trypsin activity was inhibited by addition of culture medium containing $10 \%$ FBS (Sigma-Aldrich; Merck KGaA). The cell suspension was centrifuged at $300 \mathrm{~g}$ x $5 \mathrm{~min}$ and the cell pellet was then resuspended in phosphate buffered saline without calcium and magnesium (PBS-) containing 3\% FBS to obtain single cell suspension. Separate aliquots $\left(2 \times 10^{5}\right.$ cells) were used for MSC isotype cocktail (Miltenyi Biotec $\mathrm{GmbH}$, Bergisch Gladbach, Germany), MSC phenotyping cocktail (Miltenyi Biotec $\mathrm{GmbH}$ ) or in combination with other primary monoclonal antibodies (CD44, CD29; BD Biosciences, Franklin Lakes, NJ, USA) to avoid interference with same fluorochromes. The MSC isotype cocktail comprised of fluorochrome conjugated monoclonal antibodies, namely mouse IgG1-FITC, mouse IgG1-PE, mouse IgG1-APC, mouse IgG1-PerCp and mouse IG2a-PerCp. The MSC phenotyping cocktail comprised of both positive (CD73-APC, CD90-FITC, CD105-PE) and negative (CD34/CD45/CD14/CD20-PerCp) fluorochrome conjugated monoclonal antibodies. The cells were incubated with respective antibodies at 1:10 dilution for $15 \mathrm{~min}$ at $4{ }^{\circ} \mathrm{C}$; then washed with $1 \mathrm{ml}$ of $3 \%$ FBS and centrifuged at $300 \mathrm{~g} \mathrm{x}$ 5 min. The supernatant was discarded, and the cells were resuspended in $500 \mu \mathrm{l}$ of $3 \%$ FBS before analysis using a FACS Aria III instrument (BD Biosciences), which is equipped with a $488 \mathrm{~nm}$ (blue) laser and a $561 \mathrm{~nm}$ (yellow-green) laser for uncoupled excitation and detection of FITC and PE fluorochromes.

Preparation of $h W J S C$-CM. Early passages of hWJSCs (P2-P4) were grown under standard culture conditions and the medium was changed every $48 \mathrm{~h}$. When the cells were $70 \%$ confluent, the culture medium was replaced with fresh medium and the 
cells were cultured for up to $72 \mathrm{~h}$. The hWJSC-CM was then harvested, sterilized using $0.2 \mu \mathrm{m}$ syringe filters and stored in aliquots at $4^{\circ} \mathrm{C}$ until further use (17).

Preparation of $h W J S C$ - $C L$. The hWJSCs were grown as described above, and at $80 \%$ confluence the cells were trypsinized, pelleted, washed twice in PBS, and centrifuged at $500 \mathrm{~g}$ for $5 \mathrm{~min}$. The resultant cell pellet was lysed in cell lysis buffer (Sigma-Aldrich; Merck KGaA) with a protease inhibitor cocktail. The cells were gently pipetted up and down to lyse the membranes and release the cellular contents. The cell lysate (in $2 \mathrm{ml}$ Eppendorf tubes) were then placed on ice and continuously agitated in a rocker platform for $15 \mathrm{~min}$. The cell suspension was then centrifuged at $25,000 \mathrm{~g}$ for $15 \mathrm{~min}$ and the clear supernatant was collected and stored in aliquots at $4^{\circ} \mathrm{C}$ until further use. The total protein content was quantified using a NanoDrop ${ }^{\mathrm{TM}} 2000$ spectrophotometer (NanoDrop Technologies; Thermo Fisher Scientific, Inc.) (17).

Culture of OVCAR3 cells. The commercial human ovarian cancer OVCAR3 cell line was purchased from the European Collection of Authenticated Cell Cultures (Salisbury, UK). The OVCAR3 cells were rapidly thawed in a $37^{\circ} \mathrm{C}$ water bath following the standard cell-thawing procedure and cultured at optimal conditions of $37^{\circ} \mathrm{C}$ in a $5 \% \mathrm{CO}_{2}$ incubator. The cells were cultured in low-glucose Dulbecco's Modified Eagles Medium DMEM supplemented with 10\% FBS, 2 mM Glutamax and $1 \%$ penicillin-streptomycin.

Cell morphology. OVCAR3 cells were seeded at a density of $2 \times 10^{4}$ cells/well in a $24-w e l l$ plate and tested with hWJSC-CM (25, 50 and 75\%), hWJSC-CL (5, 10 and $15 \mu \mathrm{g} / \mathrm{ml})$ and paclitaxel $(2.5,5$ and $10 \mathrm{nM})$. The control and experimental groups were then cultured at $37^{\circ} \mathrm{C}$ in a $5 \% \mathrm{CO}_{2}$ incubator for $24-72 \mathrm{~h}$ and any changes in cell morphology were observed using an inverted-phase contrast microscope (Nikon Corporation, Tokyo, Japan).

Cell proliferation. OVCAR3 cells were seeded at $2 \times 10^{4}$ cells/well in a 24 -well plate and allowed to attach overnight. The culture medium was then replaced with medium containing various concentrations of hWJSC-CM $(25,50$ and $75 \%)$, hWJSC-CL $(5,10$ and $15 \mu \mathrm{g} / \mathrm{ml})$ or paclitaxel $(2.5,5$ and $10 \mathrm{nM}$ ) for 24, 48 and $72 \mathrm{~h}$. The control cells were cultured in normal culture medium without any pharmacological agents. The cell proliferation/inhibition under various experimental conditions was analysed using the MTT assay according to the manufacturer's instructions. Briefly, the culture medium was removed and $200 \mu \mathrm{l}$ fresh medium containing $10 \mu \mathrm{l}$ MTT reagent (Sigma-Aldrich; Merck KGaA) was added, followed by incubation under standard culture conditions for up to $4 \mathrm{~h}$. The medium was removed and $200 \mu \mathrm{l}$ solubilisation reagent was added. The absorbance at $570 \mathrm{~nm}$, with a reference wavelength of $630 \mathrm{~nm}$, was measured using a SpectraMax i3 Multimode Reader (Molecular Devices, LLC, Sunnyvale, CA, USA). The differences between the treated and control groups were analyzed with one-way analysis of variance with Bonferroni's multiple comparisons post hoc analyis using SPSS version 22.0 (IBM Corp., Armonk, NY, USA). The results are presented as the mean \pm standard error of the mean from 3 replicates for individual assays and $\mathrm{P}<0.05$ was considered to indicate a statistically significant difference.

Multiplex cytokine analysis. Multiplex cytokine analysis was performed using the Human Cytokine Magnetic 30-Plex Panel (LHC6003M; Thermo Fisher Scientific, Inc.). The assay was performed on the cell culture supernatant of OVCAR3 cells collected at $48 \mathrm{~h}$ following treatment with $50 \% \mathrm{hWJSC}-\mathrm{CM}, 10 \mu \mathrm{g} / \mathrm{ml} \mathrm{hWJSC}-\mathrm{CL}$ and $5 \mathrm{nM}$ paclitaxel. The assay was performed in a 96-well plate format, according to the manufacturer's instructions. Briefly, the antibody-coated polystyrene magnetic beads in solution (with different spectral intensities) were vortexed for $30 \mathrm{sec}$ and sonicated for $30 \mathrm{sec}$ for $5 \mathrm{~min}$ (at $50 \mathrm{~Hz} ; 37^{\circ} \mathrm{C}$ ). Then $25 \mu \mathrm{l}$ of the antibody-coated polystyrene magnetic beads was added to the 96 well flat bottom plate and washed twice with $1 \mathrm{X}$ wash buffer. The standards (1:3 serial dilution) and samples (undiluted cell culture supernatants) were prepared, added to the beads and incubated at room temperature (RT) on an orbital shaker at 500 RPM for $2 \mathrm{~h}$ to enable the capture of analytes. The plate was then incubated at RT with biotinylated detection antibodies (100 $\mu \mathrm{l} /$ well) for $1 \mathrm{~h}$, followed by streptavidin-R-phycoerythrin antibodies (100 $\mu \mathrm{l} /$ well) for $30 \mathrm{~min}$ (both antibodies are supplied with the kit-LHC6003M as $10 \mathrm{X}$ concentration and were diluted to $1 \mathrm{X}$ using respective diluents). Between incubations with different antibodies, the plate was washed twice with wash buffer. All washing steps were performed using a hand-held magnetic bottom in order to facilitate the retention of the magnetic antibody beads. Finally, the plate was washed three times, the beads resuspended in wash buffer and analysed using the Luminex MAGPIX ${ }^{\circledR}$ instrument (Luminex Corporation, Austin, TX, USA). The data obtained were analysed using the Luminex $\mathrm{xPONENT}^{\circledR}$ multiplex assay analysis software (v.4.2.1324.0, Luminex Corporation).

Heatmaps and hierarchical cluster analysis. The differential expression of cytokines, chemokines and growth factors, calculated based on the $\log _{2}$-fold change between the control and the experimental groups, was used as an input for Genesis Software (Graz University of Technology, Graz, Austria) (19) to generate the heatmaps. Furthermore, the hierarchical clustering function with the complete linkage method in Genesis was used to generate the hierarchical clusters of pro- and antitumour cytokines, chemokines and growth factors.

\section{Results}

Derivation and culture of hWJSCs. The hWJSCs were successfully derived from all human umbilical cords and their primary cultures were established. The hWJSCs appeared as epitheliod cells that resembled short fibroblasts in the initial passages, and transformed to long fibroblasts in subsequent passages (Fig. 1A-F).

Culture of OVCAR3 cells. Following thawing, the OVCAR3 cells exhibited minimal attachment and slow growth. However, with subsequent passages they displayed improved proliferation rates and demonstrated their characteristic epithelial morphology in culture (Fig. $1 \mathrm{G}$ and $\mathrm{H}$ ). 

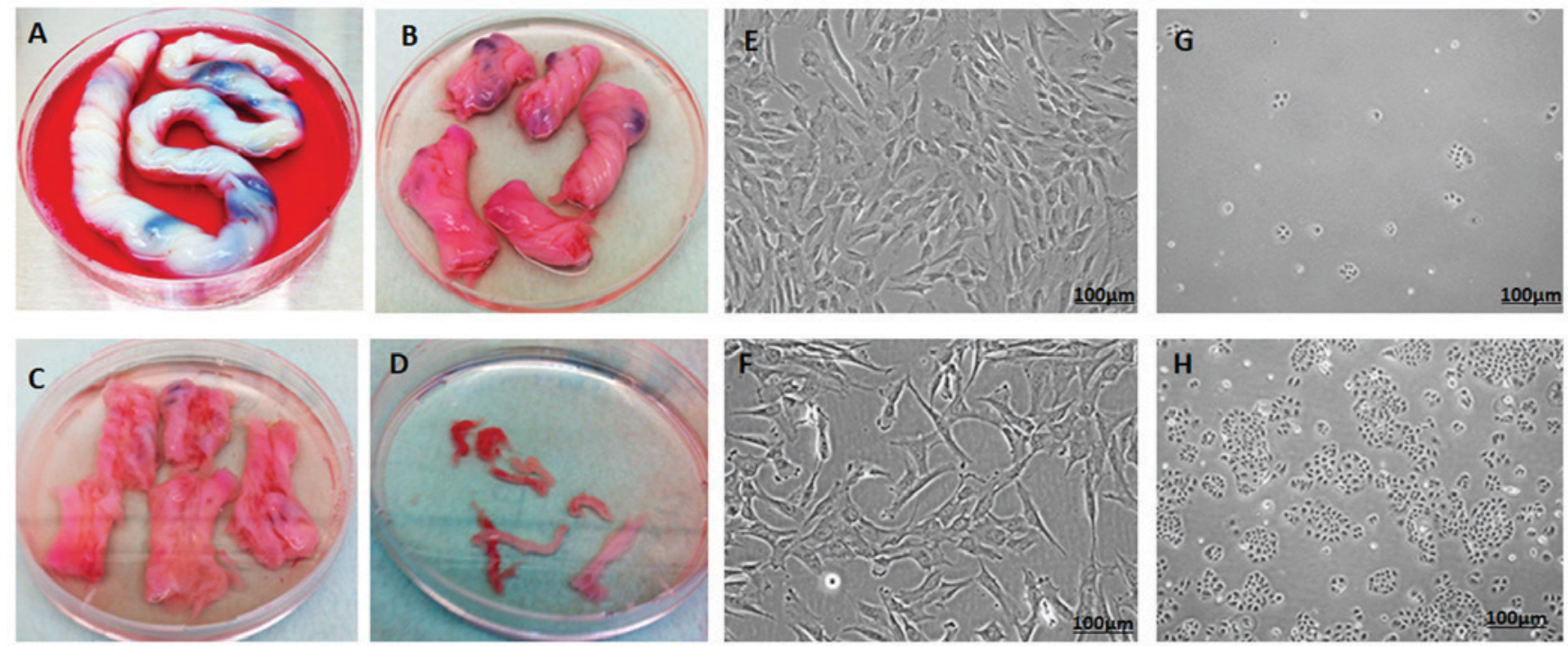

Figure 1. Representative images of human Wharton's Jelly stem cells (hWJSCs) derivation procedure, showing the (A) whole umbilical cord, (B) umbilical cord pieces of $\sim 2 \mathrm{~cm}$ length, (C) umbilical cord pieces opened lengthwise and (D) the separated umbilical cord blood vessels. Representative phase contrast images of the hWJSCs in (E) early and (F) late passages showing the characteristic short and long fibroblastic appearance. The commerical human ovarian cancer cell line (OVCAR3) in $(\mathrm{G})$ early culture and $(\mathrm{H})$ later subculture showing the characteristic epitheloid cells.

Surface marker characterization of hWJSCs. The derived cells analyzed for CD markers expression demonstrated high percentages of positive MSC related CD markers, namely CD73 (99.54\%), CD90 (91.67\%), CD105 (84.67\%), CD44 $(84.25 \%)$ and CD29 (99.76\%) compared with respective isotype matched controls (Fig. 2A and B). These cells were negative for CD34 and CD45, the haematopoietic stem cell related $\mathrm{CD}$ markers (Fig. 2C).

Morphology of OVCAR3 cells (phase contrast microscopy). The OVCAR3 cells exhibited various morphological changes leading to cell death following exposure to hWJSC-CM (25, 50 and $75 \%$ ); hWJSC-CL $(5,10$ and $15 \mu \mathrm{g} / \mathrm{ml})$ and paclitaxel $(2.5,5$ and $10 \mathrm{nM})$ for 24,48 and $72 \mathrm{~h}$ (Fig. 3A-C). An overall decrease in live cells was observed, demonstrating morphological changes, including cell shrinkage, membrane damage and cell death. These cellular changes were more pronounced in the cells treated with paclitaxel, followed by those treated with hWJSC-CL and hWJSC-CM. The morphological changes and cell death were time- and concentration-dependent.

OVCAR3 cell proliferation (MTT assay). A concentration-dependent decrease in the proliferation of the OVCAR3 cells was revealed following exposure to hWJSC-CM (25, 50 and $75 \%$ ); hWJSC-CL $(5,10$ and $15 \mu \mathrm{g} / \mathrm{ml})$ and paclitaxel $(2.5,5$ and $10 \mathrm{nM})$ for 24,48 and $72 \mathrm{~h}$. The mean decrease in OVCAR3 cells observed following treatment with 25, 50 and $75 \%$ hWJSC-CM was $7.14,13.27$ and $26.53 \%$, respectively at $24 \mathrm{~h} ; 7.48,17.76$ and $36.45 \%$, respectively at $48 \mathrm{~h}$; and 8.93 , 26.79 and $45.54 \%$, respectively at $72 \mathrm{~h}$ (Fig. 3D). The mean decrease in OVCAR3 cells observed with the 50\% hWJSC-CM at 48 and $72 \mathrm{~h}$, and the $75 \% \mathrm{hWJSC}-\mathrm{CM}$ atall three time points was statistically significant $(\mathrm{P}<0.05)$ compared with the control.

The mean decrease in OVCAR3 cells following treatment with 5, 10 and $15 \mu \mathrm{g} / \mathrm{ml}$ hWJSC-CL was $12.75,30.39$ and $39.22 \%$, respectively at $24 \mathrm{~h} ; 20.69,40.52$ and $51.72 \%$, respectively at $48 \mathrm{~h}$; and $16.80,51.20$ and $58.57 \%$, respectively at $72 \mathrm{~h}$ (Fig. 3E). The mean decrease observed with all three concentrations of hWJSC-CL at all three time points was statistically significant $(\mathrm{P}<0.05)$ compared with the control.

The mean decrease in OVCAR3 cells observed with 2.5, 5 and $10 \mathrm{nM}$ paclitaxel was $34.29,48.57$ and $58.10 \%$, respectively at $24 \mathrm{~h} ; 43.33,48.89$ and $62.22 \%$, respectively at $48 \mathrm{~h}$; and $53.16,72.15$ and $79.75 \%$, respectively at $72 \mathrm{~h}$ (Fig. 3F). The mean decrease following treatment with all three concentrations of paclitaxel at all three time points was statistically significant $(\mathrm{P}<0.05)$ compared with the control.

Cytokine secretion profile in OVCAR3 cells treated with $h W J S C$ extracts. The analysis of the cell culture supernatant of OVCAR3 cells following treatment with hWJSC-CM (50\%), hWJSC-CL (10 $\mu \mathrm{g} / \mathrm{ml})$ and paclitaxel $(5 \mathrm{nM})$ for $48 \mathrm{~h}$, demonstrated a decrease in the secreted cytokines, chemokines and growth factors compared with the untreated control.

The levels of cytokines that are reported to be involved in tumour growth, invasion and migration, namely interleukin (IL)-1 $\beta$, IL-4, IL-6, IL-8, IL-10, IL-13, IL-17, interferon (IFN)- $\gamma$, tumour necrosis factor $\alpha$ (TNF- $\alpha)$ and granulocyte colony-stimulating factor (G-CSF), were decreased following treatment with hWJSC extracts and paclitaxel (Fig. 4). The mean decrease following treatment with $5 \mathrm{nM}$ paclitaxel, $50 \%$ hWJSC-CM and $10 \mu \mathrm{g} / \mathrm{ml} \mathrm{hWJSC}-\mathrm{CL}$ was as follows: IL-1 $\beta$ by $14.73,22.33$ and $26.17 \%$; IL-4 by $55.56,50.48$ and $45.40 \%$; IL- 6 by $92.55,87.38$ and $83.54 \%$; IL- 8 by $95.61,81.08$ and $46.97 \%$; IL-10 by $73.78,69.90$ and $66.16 \%$; IL-13 by 42.74 , 24.51 and $42.74 \%$; IL-17 by $15.27,7.60$ and $19.17 \%$; TNF- $\alpha$ by $35.59,46.23$ and $46.23 \%$; and G-CSF by $19.73,7.55$ and $15.39 \%$ respectively. Of these, the decrease in IL-1 $\beta$ with hWJSC-CL alone; IL-4, IL-6, IL-8, IL-10, IL-13, IL-17 and TNF- $\alpha$ with paclitaxel, hWJSC-CM and hWJSC-CL; and G-CSF with paclitaxel alone, were statistically significant $(\mathrm{P}<0.05)$ compared with the control. 

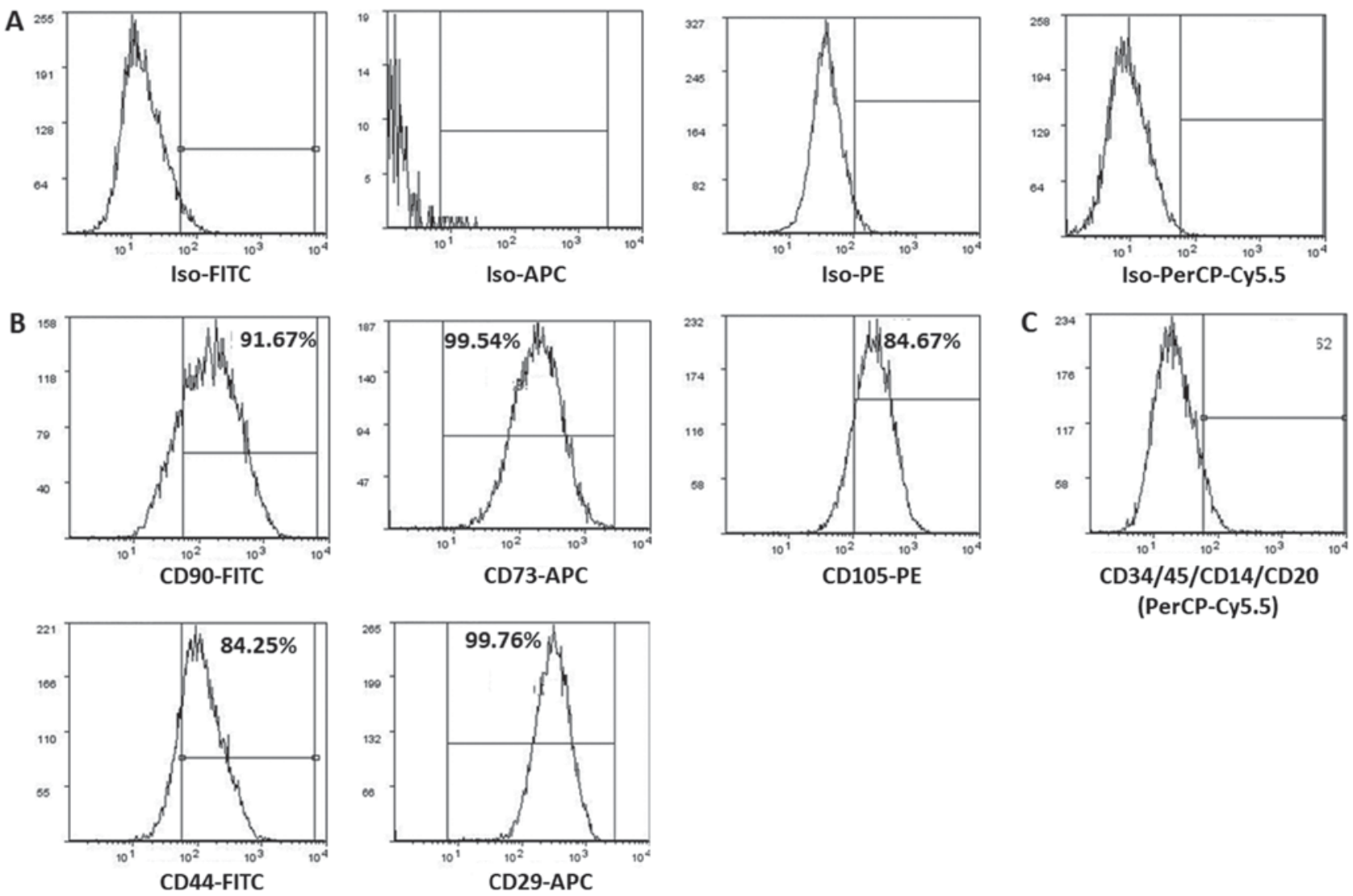

(PerCP-Cy5.5)

Figure 2. Representative Fluorescent activated cell-sorting analysis showing the CD marker expression pattern in human Wharton's Jelly stem cells (hWJSCs). (A) Respective isotype controls; (B) Middle panel: MSC positive CD markers; (C) lower panel: MSC negative CD markers.
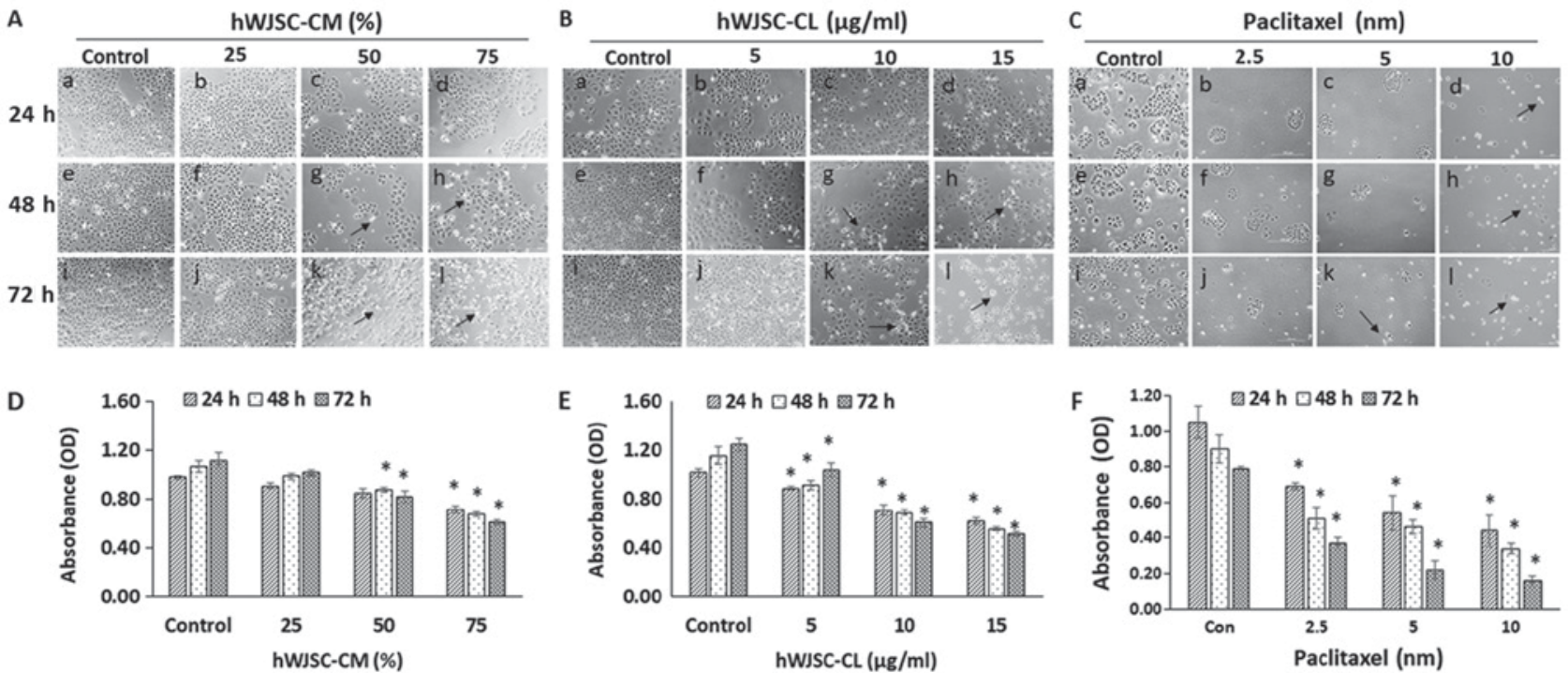

Figure 3. Representative phase contrast images of OVCAR3 cells treated with (Aa-Al) hWJSC-CM; (Ba-Bl) hWJSC-CL and (Ca-Cl) paclitaxel for (a-d) 24 h; (e-h) $48 \mathrm{~h}$ and (i-1) $72 \mathrm{~h}$, showing increase in dead translucent cells (indicated by thin black arrows) with increasing time and concentrations of hWJSC-CM, hWJSC-CL and paclitaxel. Cell proliferation assay of OVCAR3 cells treated with (D) hWJSC-CM; (E) hWJSC-CL and (F) paclitaxel for 24 to 72 h. The OVCAR3 cell proliferation was inhibited by hWJSC-CM (at higher concentrations), hWJSC-CL and the standard anticacner drug paclitaxel that were both time and concentration dependent. The values are expressed as mean \pm SEM of three different experiments. "P<0.05 vs. the control. hWJSC-CM, human Wharton's jelly stem cells conditioned medium; hWJSC-CL, human Wharton's jelly stem cell lysate.

The levels of cytokines that are reported to exhibit antitumour effects, namely IL-1 receptor antagonist (IL-1RA), IL-2, IL-2 receptor (IL-2R), IL-5, IL-7, IL-12, IL-15, IFN- $\alpha$, IFN- $\gamma$ and granulocyte-macrophage colony-stimulating factor
(GM-CSF), either increased or decreased following treatment with hWJSC extracts and paclitaxel (Fig. 5). Of these, only the changes in IL-1RA with paclitaxel (32.47\% increase), hWJSC-CM (32.47\% increase) and hWJSC-CL (16.47\% 

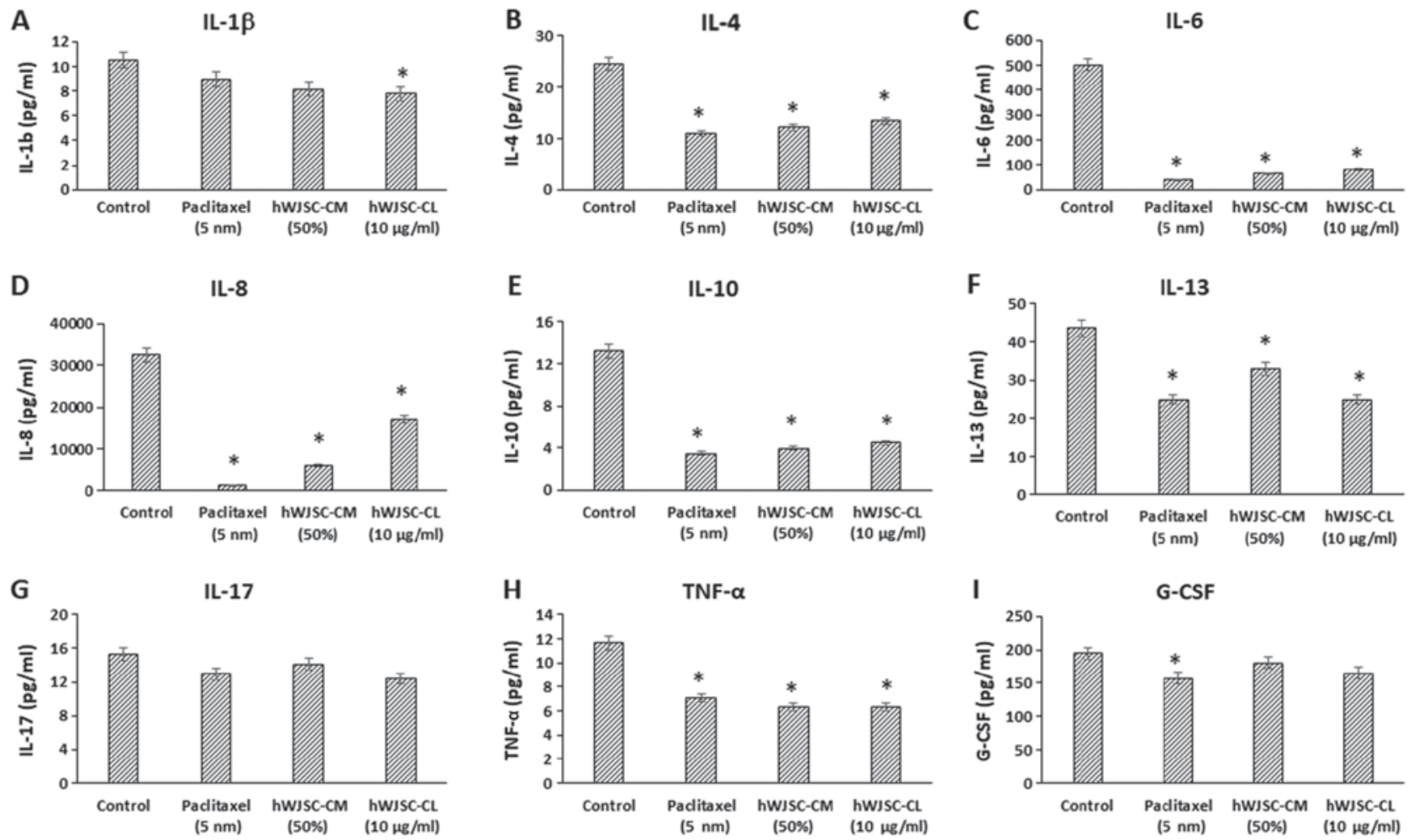

Figure 4. Expression levels of cytokines in the cell culture supernatant of OVCAR3 cells following treatment with hWJSC-CM (50\%), hWJSC-CL (10 $\mu \mathrm{g} / \mathrm{ml})$ and paclitaxel (5 nm) for $48 \mathrm{~h}$, and analyzed using multiplex cytokine assay. The following cytokines namely, (A) IL-1 , (B) IL-4, (C) IL-6, (D) IL-8, (E) IL-10, (F) IL-13, (G) IL-17, (H) TNF- $\alpha$ and (I) G-CSF that are reported to increase tumour growth and progression were decreased. The values are expressed as mean \pm SEM of three different experiments. "P $<0.05$ vs. the control. hWJSC-CM, human Wharton's jelly stem cells conditioned medium; hWJSC-CL, human Wharton's jelly stem cell lysate.
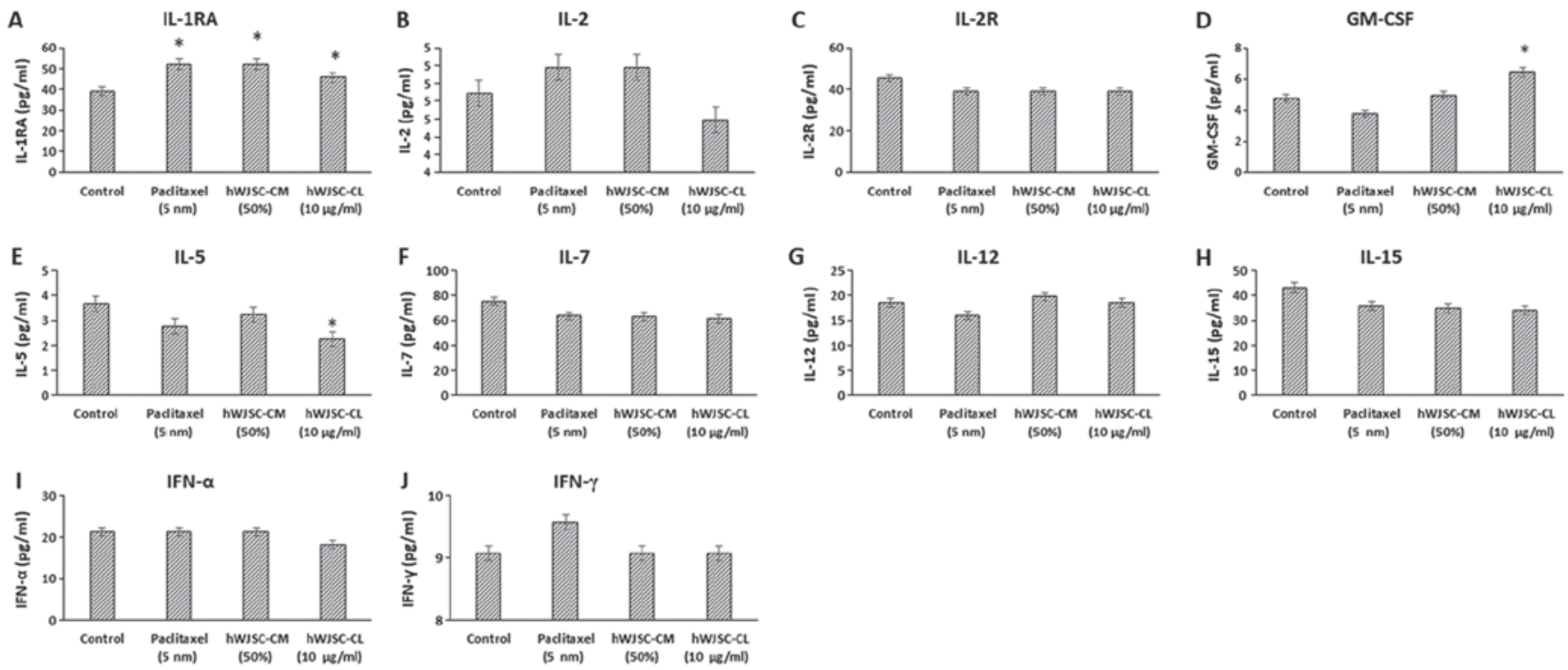

Figure 5. Expression levels of cytokines in the cell culture supernatant of OVCAR3 cells following treatment with hWJSC-CM (50\%), hWJSC-CL (10 $\mu \mathrm{g} / \mathrm{ml})$ and paclitaxel $(5 \mathrm{~nm})$ for $48 \mathrm{~h}$, and analyzed using multiplex cytokine assay. The following cytokines namely, (A) IL-1RA, (B) IL-2, (C) IL2R, (D) GM-CSF, (E) IL-5, (F) IL-7, (G) IL-12, (H) IL-15, (I) IFN- $\alpha$ and (J) IFN- $\gamma$ were either increased or mildly decreased. The values are expressed as mean \pm SEM of three different experiments. " $\mathrm{P}<0.05$ vs. the control. hWJSC-CM, human Wharton's jelly stem cells conditioned medium; hWJSC-CL, human Wharton's jelly stem cell lysate.

increase); GM-CSF with hWJSC-CL (35.08\% increase); and IL-5 with hWJSC-CL (38.66\% decrease) were statistically significant $(\mathrm{P}<0.05)$ compared with the control.

The levels of chemokines that are primarily associated with tumour progression, namely monocyte chemoattractant protein 1 (MCP-1); macrophage inflammatory protein (MIP)-1 $\alpha$; MIP-1 $\beta$; Regulated Upon Activation, Normally T-Expressed, and Secreted (RANTES); monokine induced by INF- $\gamma$ (MIG); INF- $\gamma$ induced protein (IP-10) and Eotaxin, decreased following treatment with hWJSC extracts and 

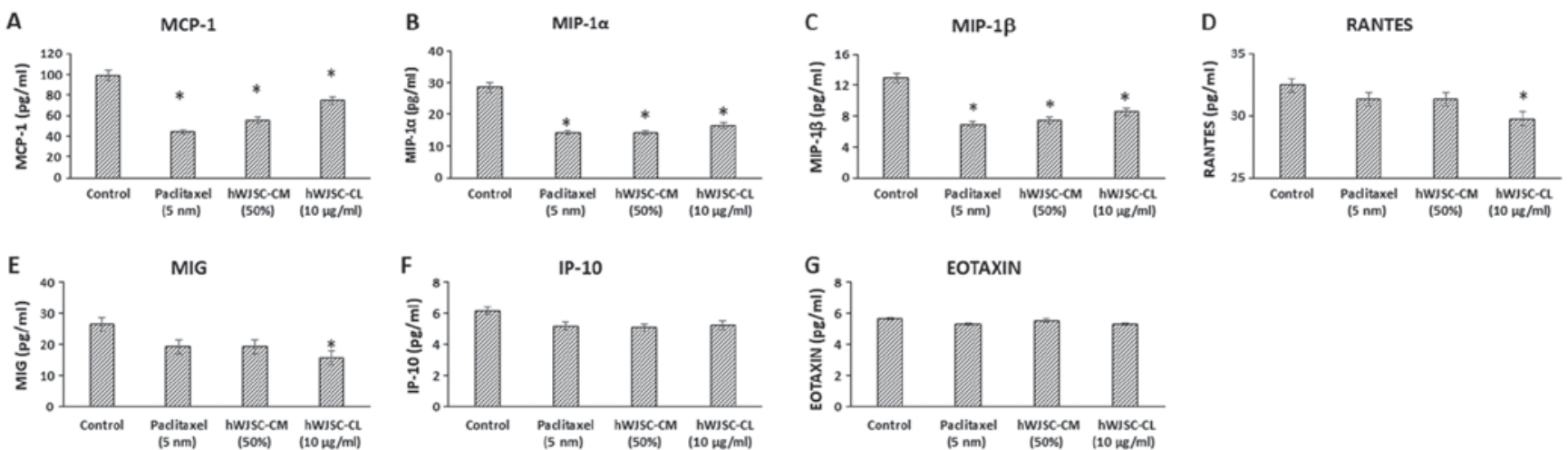

Figure 6. Expression levels of chemokines in the cell culture supernatant of OVCAR3 cells following treatment with hWJSC-CM (50\%), hWJSC-CL (10 $\mu \mathrm{g} / \mathrm{ml})$ and paclitaxel $(5 \mathrm{~nm})$ for $48 \mathrm{~h}$, and analyzed using multiplex cytokine assay. The following chemokines namely, (A) MCP-1, (B) MIP-1 $\alpha$, (C) MIP-1 $\beta$, (D) RANTES, (E) MIG, (F) IP-10 and (G) Eotaxin, that are reported to increase tumour growth and progression were decreased. The values are expressed as mean \pm SEM of three different experiments. "P $<0.05$ vs. the control. hWJSC-CM, human Wharton's jelly stem cells conditioned medium; hWJSC-CL, human Wharton's jelly stem cell lysate.
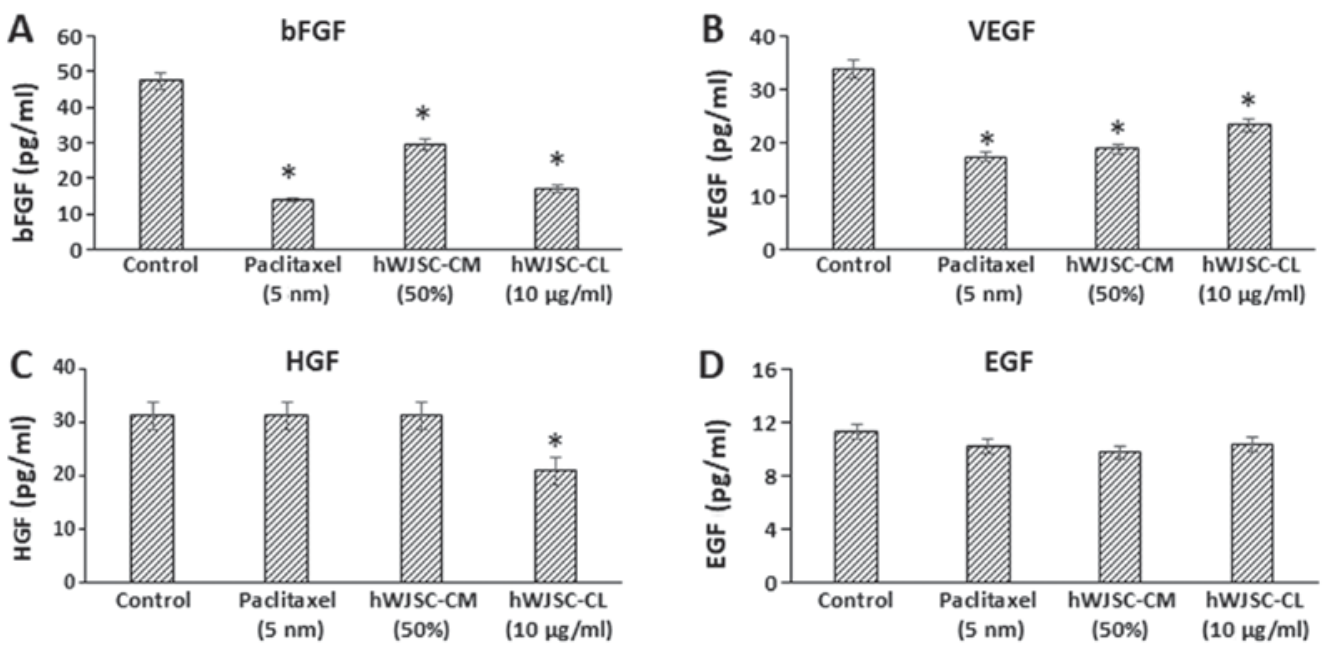

Figure 7. Expression levels of growth factors in the cell culture supernatant of OVCAR3 cells following treatment with hWJSC-CM (50\%), hWJSC-CL $(10 \mu \mathrm{g} / \mathrm{ml})$ and paclitaxel $(5 \mathrm{~nm})$ for $48 \mathrm{~h}$, and analyzed using multiplex cytokine assay. The following growth factors namely, (A) bFGF, (B) VEGF, (C) HGF and (D) EGF, that are reported to increase tumour growth and progression were decreased. The values are expressed as mean \pm SEM of three different experiments. "P<0.05 vs. the control. hWJSC-CM, human Wharton's jelly stem cells conditioned medium; hWJSC-CL, human Wharton's jelly stem cell lysate.

paclitaxel (Fig. 6). The mean decrease was as follows: MCP-1 by $55.36,43.87$ and $24.20 \%$; MIP- $1 \alpha$ by $50.65,50.65$ and $42.13 \%$; MIP-1 13 by $46.29,42.27$ and $34.31 \%$; RANTES by $3.47,3.47$ and $8.39 \%$; MIG by $27.45,27.43$ and $40.78 \%$; IP-10 by $15.90,17.73$ and $14.90 \%$; and Eotoxin by $6.17,2.04$ and $6.18 \%$, following treatment with $5 \mathrm{nM}$ paclitaxel, $50 \%$ hWJSC-CM and $10 \mu \mathrm{g} / \mathrm{ml} \mathrm{hWJSC}-\mathrm{CL}$, respectively. Of these, only the decrease in MCP-1, MIP- $1 \alpha$ and MIP-1 $\beta$ with paclitaxel, hWJSC-CM and hWJSC-CL; and RANTES and MIG with hWJSC-CL was statistically significant $(\mathrm{P}<0.05)$ compared with the control.

The majority of the growth factors known to support oncogenic activity, namely bFGF, vascular endothelial growth factor (VEGF), hepatocyte growth factor (HGF) and epidermal growth factor (EGF), decreased following treatment with hWJSC extracts and paclitaxel (Fig. 7). The mean decrease was as follows: bFGF by $70.65,37.41$ and $63.98 \%$; VEGF by 48.92, 44.49 and $31.20 \%$; and EGF by $9.59,13.68$ and $8.34 \%$ following treatment with $5 \mathrm{nM}$ paclitaxel, $50 \% \mathrm{hWJSC}-\mathrm{CM}$ and $10 \mu \mathrm{g} / \mathrm{ml} \mathrm{hWJSC}-\mathrm{CL}$, respectively. HGF only exhibited a decrease by $33.11 \%$ with hWJSC-CL. Of these, only the changes observed with bFGF, VEGF and HGF were statistically significant $(\mathrm{P}<0.05)$ compared with the control.

Heatmaps and hierarchical cluster analysis. The mean expression values of cytokines in OVCAR3 cells treated with $50 \% \mathrm{hWJSC}-\mathrm{CM}, 10 \mu \mathrm{g} / \mathrm{ml} \mathrm{hWJSC}-\mathrm{CL}$ and $5 \mathrm{nM}$ paclitaxel displayed variable fold changes as depicted by heatmaps, where the blue and red colours indicate the lower and higher expression limits, respectively (Fig. 8A-D). Certain oncogenic cytokines revealed high fold changes with paclitaxel (IL-1 $\beta$ alone); hWJSC-CM (G-CSF > IL-17 > IL-13); and hWJSC-CL (IL-8 alone), whereas other cytokines revealed moderate to low fold changes (Fig. 8A). Certain antitumour cytokines exhibited high fold changes with paclitaxel (IFN- $\gamma>$ IL-1RA $>$ IL-2>IFN- $\alpha$ ); hWJSC-CM (IL-12>IL-1RA $>$ IL-2 $>$ IFN- $\alpha$ $>$ IL-5>GM-CSF); and hWJSC-CL (GM-CSF $>$ IL-12), whereas other cytokines revealed moderate to low fold changes 

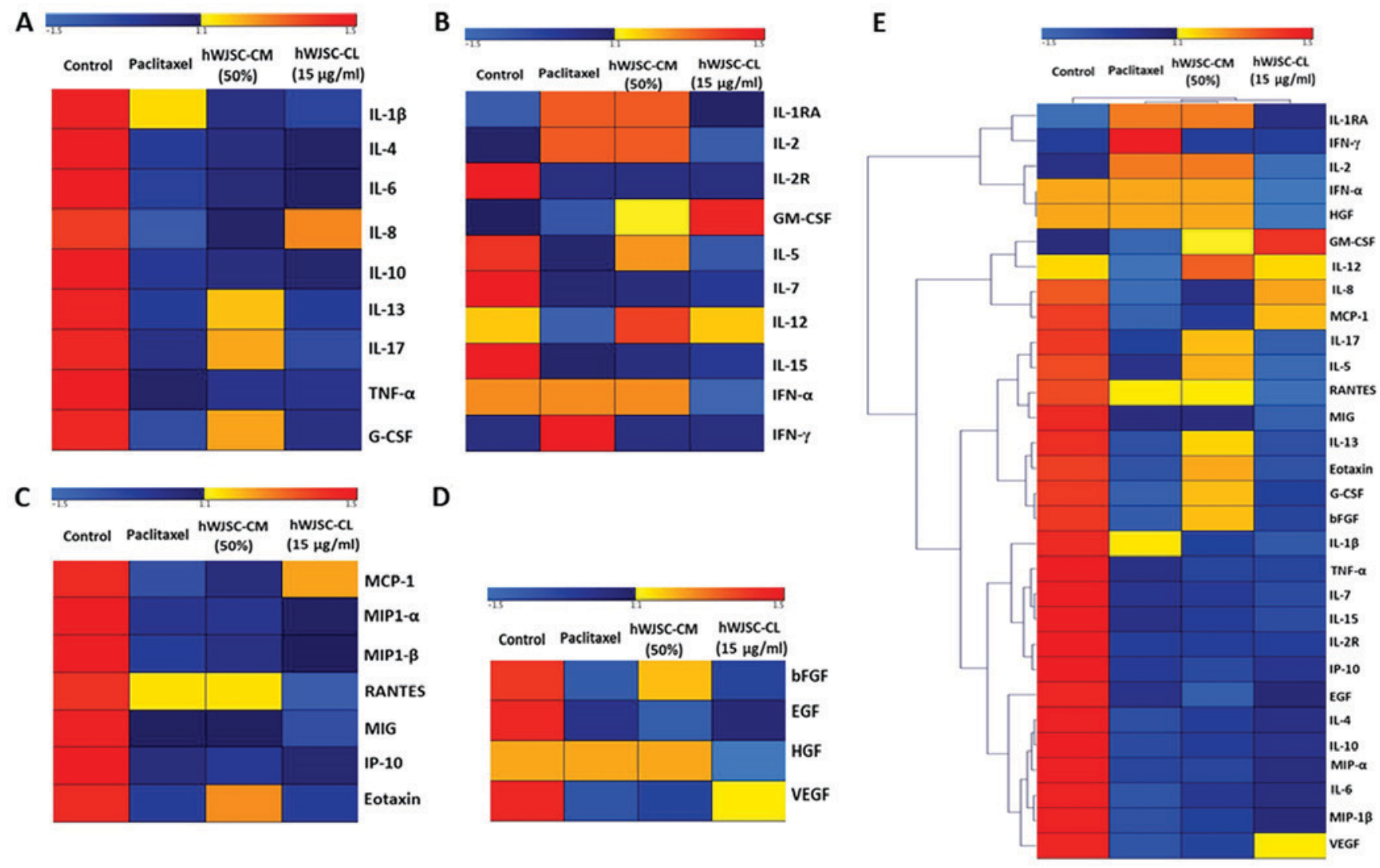

Figure 8. Heatmap and hierarchical cluster analysis of Cytokines, Chemokines and Growth Factors using Genesis Software. Heatmap of the differentially regulated (A) pro-inflammatory cytokines; (B) anti-inflammatory cytokines; (C) chemokines and (D) growth factors. (E) Hierarchical Clustering of the differentially regulated cytokines showing the major and minor clusters of closely interlinked cytokines.

(Fig. 8B). Certain chemokines exhibited high fold changes with paclitaxel (RANTES alone); hWJSC-CM (RANTES >Eotaxin); and hWJSC-CL (MCP-1 alone), whereas other chemokines revealed moderate to low fold changes (Fig. 8C). Certain growth factors exhibited higher fold changes with paclitaxel (HGF alone); hWJSC-CM (HGF $>$ bFGF); and hWJSC-CL (VEGF alone), whereas other growth factors revealed moderate to low fold changes (Fig. 8D). Hierarchical clustering was determined based on the level of fold changes exhibited by the cytokines, chemokines and growth factors, and the distances within and between each cluster (Fig. 8E). A total of 29 clusters consisted of three major clusters linked to 7 small sub-clusters, of which each was linked to $\geq 2$ closely associated cytokines, chemokines or growth factors (Fig. 7E).

\section{Discussion}

Tumour cells develop abilities to escape the immune surveillance of the body and manage to proliferate, invade local or adjacent tissues, and migrate to distant sites. MSCs have gained a lot of attraction as an anticancer agent, with certain protocols undergoing clinical trials (9). MSCs can be modified to express antitumour cytokines, chemokines, growth factor antagonists and apoptosis-inducing agents. Given their tumour tropism, modified or naïve MSCs have been used against a number of tumours, including melanoma, colon cancer, hepatic cancer, lung cancer, breast cancer, prostate cancer and ovarian cancer $(12,20)$. Compared with other currently available
MSCs, the hWJSCs isolated from within the human umbilical cord present several advantages, including high proliferative potential, long telomeres and multipotency (16). The present study demonstrated the inhibition of the growth and proliferation of OVCAR3 cells in vitro in freshly prepared hWJSC-CM and hWJSC-CL, which may partly be mediated by the soluble factors/cytokines in the hWJSC extracts.

Overall, cancer is an inflammatory condition, and cell growth, differentiation, migration and signaling are regulated by numerous molecules, including cytokines, chemokines and growth factors. The cytokine expression pattern may vary according to the tumour type, and they can serve as biomarkers for diagnosis and prognosis (14). The present study revealed a decrease in cytokines that are reported to have cancer-promoting properties, namely IL- $1 \beta$, IL-4, IL-6, IL-8, IL-10, IL-13, IL-17, TNF- $\alpha$ and G-CSF. A prospective randomized placebo-controlled multicenter trial that evaluated the association between proinflammatory cytokines and cancer incidence identified IL-1 $\beta$, IL- 6 and TNF- $\alpha$ to be associated with increased risk of cancer (21). Cathespin, a cysteine protease, promotes tumour growth and proliferation, and IL-4 induces cathespin activity in tumour-associated macrophages (22). High levels of IL-6 and IL-8 were dectected in patients with EOC and were associated with poor prognosis and short disease-free survival time (23). Increased levels of IL-10 have been reported in patients with ovarian cancer, and IL-10, being immunosuppresive, contributes to the disease progression (24). IL-13 enhanced the invasion of cancer cells that were 
IL-13 receptor subunit $\alpha-2$ (IL-13R $\alpha 2)^{+}$, but not IL-13R $\alpha 2^{-}$, in a murine model of human pancreatic cancer (25). Increased levels of TNF- $\alpha$ in the tumour environment were associated with ovarian cancer progression in humans and mice in a 1L-17-dependent manner (26). Furthermore, the treatment of breast cancer MDA-MB231 and MDA-MB435 cell lines with IL-17 resulted in enhanced Matrigel invasion (27). The G-CSF receptor was highly expressed in serous epithelial ovarian tumour and the stimulation of G-CSFR ${ }^{+}$OVCA429 and TOV21 G cells with G-CSF enhanced cell migration, mediated by the tyrosine-protein kinase JAK2/signal transducer and activator of transcription 3 signaling pathway (28). There appears to be efficient signaling and interaction between the oncogenic cytokines, and their inhibiton, or a decrease in their expression, as accomplished by hWJSC extracts, may be beneficial.

In the present study, the cytokines associated with antitumour effects, namely IL-1RA, IL-2, IL2R, GM-CSF, IL-5, IL-7, IL-12, IL-15 IFN- $\alpha$ and IFN- $\gamma$, either increased or slightly decreased following treatment with hWJSC-CM and hWJSC-CL. Whereas IL-1 cytokines promote tumour growth and progression, IL-1RA, a member of the IL-1 family, blocks the IL-1 receptor competitively and supports tumour inhibiton (29). It has previously been reported that IL-1RA also inhibits the expression of VEGF in colorectal carcinoma (30). Adoptive T cell therapy appears to be a promising strategy in the inhibition of EOC. Tumour infiltrating lymphocytes (TILs) were expanded in freshly resected ovarian tumours using a combination of IL-2, anti-cluster of differentiation (CD)3 and anti-CD28 magnetic beads, and these TILs demonstrated tumour-inhibitory effects (31). In a rodent model of orthoptic liver tumour, a combination of IL-2 and GM-CSF administered intratumourally or intravenously was more effective than IL-2 monotherapy against the tumour, and these effects were mediated by $\mathrm{CD} 8^{+} \mathrm{T}$ cells, natural killer $\mathrm{T}$ cells and macrophages (32). The efficacy of IL-2 depends on its potential to expand regulatory $\mathrm{T}$ cells, and this is mediated by its receptor, IL-2R, which directs IL-2 back to the cell surface (33). IL-5 was demonstrated to be predominantly expressed in benign ovarian neoplasms (14) and the antitumour effects of GM-CSF were revealed to be mediated by cytokine receptors shared by IL3 and IL-5 (34). The levels of IL-7, a cytokine essential for the adaptive immune response, were significantly decreased in the ascites compared with the plasma of patients with advanced ovarian cancer (35). Furthermore, the administration of cytotoxic T lymphocytes cultured with IL-7 and IL-15 led to regression of melanoma and mammary tumours in a murine model, compared with those cultured with IL-12 alone (36). IFN $-\alpha$ and IFN $-\gamma$ have been used intraperitonealy (cytokine therapy) against ovarian cancer with promising results; autologus monocytes infusion (cellular therapy) has also been reported to have antitumour effects, therefore the combination of cytokine and cellular therapy may help overcome resistant tumours (37).

The chemokines MCP-1, MIP-1 $\alpha$, MIP-1 $\beta$, RANTES, MIG, IP-10 and Eotaxin, which are associated with tumour growth and proliferation, decreased following treatment with hWJSC extracts in the present study. MCP-1, MIP-1 $\beta$ and RANTES are highly expressed in ovarian cancers having the presence of $\mathrm{T}$ cells intraepithelially or in the tumour microenvironment, whereas IP-10 is expressed in tumours even in the absence of tumour-infiltrating T cells (38). MCP-1 and MIP-1 $\alpha$ are expressed in a number of tumour tissues and are associated with the regulation of cancer progression (39). Increased overall survival was associated with a high expression of MIG and IP-10 in high grade serous ovarian cancer, and the tumour-suppresive effects were mediated by the recruitment of tumour-infiltrating lymphocytes (40).

The growth factors bFGF, EGF, HGF and VEGF are implicated in tumour cell proliferation, growth and differentiation. Combined treatment of VEGF and HGF, or VEGF, HGF and EGF was revealed to increase telomerase activity in ovarian cancer cell lines (41), demonstrating the role of these growth factors in tumour survival and progression. In the present study, the levels of the majority of the cytokines, chemokines and growth factors that have oncogenic effects decreased following treatment with hWJSC extracts.

In conclusion, the tumour microenvironment serves an important role in tumor progression or inhibibtion via cytokine regulation, and MSCs and/or their secretory products can contribute to tumour inhibition by modifying molecular signalling pathways. The higher fold changes observed in the heatmap with anti- and pro-oncogenic chemokines and growth factors, and the hierarchical clustering between them, indicate that hWJSC extracts inhibit OVCAR3 cells in vitro in a coordinated manner, mediated by cytokines. MSCs and their secretome are known to arrest various tumours by epithelial mesenchymal transition inhibition, immune regulation, extracellular matrix remodelling and through paracrine effects (42). Given the inhibitory effects of tumour-promoting cytokines, the hWJSC extracts may be useful in the inhibition of solid tumours. Unlike other existing stem cell types the hWJSCs has several advantages as they, (i) can be harvested in abundance without infliciting any pain as they are derived from umbilical cords obtained following delivery; (ii) are highly proliferative with wide differentiation potenital; (iii) have no/less ethical constraints compared to human embryonic stem cells; (iv) are hypo-immunogeneic and non-tumorigenic (43). However, evaluation on a single cancer line is a limitiation to the present study and additional studies on different types of cancer cell lines will be required to understand the real potential of hWJSCs in cancer inhibition.

\section{Acknowledgements}

The authors acknowledge with thanks the King Abdulaziz City for Science and Technology (KACST), Riyadh, Kingdom of Saudi Arabia for the financial support (grant no. AT-34330). We also acknowledge the Science and Technology unit, King Abdulaziz University for the technical support; the Department of Obstetrics and Gynaecology, King Abdulaziz University Hospital for providing the clinical material and the Centre of Excellence in Genomic Medicine Research (CEGMR) for providing the logistics.

\section{Funding}

The present study was funded by the King Abdulaziz City for Science and Technology (KACST), Riyadh, Kingdom of Saudi Arabia (grant no. AT-34-330). 


\section{Availability of data and materials}

All data generated and analysed in the present study are included in this article.

\section{Authors' contributions}

GK was involved in conceptualization, intellectual contribution, statistical evaluation and manuscript writing. KHWS and $\mathrm{NA}$ are the clinicians and were involved in providing clinical materials/information and intellectual support. RK, FA, MR, MIN, PNP and MAQ were involved in assisting the experimental work, data analysis and manuscript editing.

\section{Ethics approval and consent to participate}

The present study was performed in accordance with the recommendations of the Bioethics Committee of the King Abdulaziz University, Jeddah, Saudi Arabia. All subjects provided written informed consent, in accordance with the Declaration of Helsinki. The protocol for the derivation and use of hWJSCs, and the commercial human ovarian cancer cell line (OVCAR3) was approved by the Bioethics Committee of the King Abdulaziz University (approval no. 33-15/KAU).

\section{Patient consent for publication}

Not applicable.

\section{Competing interests}

The authors declare that they have no competing interests.

\section{References}

1. Siegel RL, Miller KD and Jemal A: Cancer statistics, 2017. CA Cancer J Clin 67: 7-30, 2017.

2. Yang JY, Yoshihara K, Tanaka K, Hatae M, Masuzaki H, Itamochi H; Cancer Genome Atlas (TCGA) Research Network, Takano M, Ushijima K, Tanyi JL, et al: Predicting time to ovarian carcinoma recurrence using protein markers. J Clin Invest 123 3740-3750, 2013

3. Jemal A, Siegel R, Xu J and Ward E: Cancer statistics, 2010. CA Cancer J Clin 60: 277-300, 2010.

4. Holschneider $\mathrm{CH}$ and Berek JS: Ovarian cancer: Epidemiology, biology, and prognostic factors. Semin Surg Oncol 19: 3-10, 2000.

5. Rosenberg L, Palmer JR, Zauber AG, Warshauer ME, Lewis JL Jr, Strom BL, Harlap S and Shapiro S: A case-control study of ora contraceptive use and invasive epithelial ovarian cancer. Am J Epidemiol 139: 654-661, 1994.

6. Barbieri F, Bajetto A and Florio T: Role of chemokine network in the development and progression of ovarian cancer: A potential novel pharmacological target. J Oncol 2010: 426956, 2010.

7. Ren L, Xiao L, Hu J, Li Z and Wang Z: MDR1 and MDR3 genes and drug resistance to cisplatin of ovarian cancer cells. J Huazhong Univ Sci Technolog Med Sci 27: 721-724, 2007.

8. Wu J, Qu Z, Fei ZW, Wu JH and Jiang CP: Role of stem cell-derived exosomes in cancer. Oncol Lett 13: 2855-2866, 2017.

9. Mohr A and Zwacka R: The future of mesenchymal stem cell-based therapeutic approaches for cancer-From cells to ghosts. Cancer Lett 414: 239-249, 2018.

10. D'souza N, Burns JS, Grisendi G, Candini O, Veronesi E, Piccinno S, Horwitz EM, Paolucci P, Conte P and Dominici M: MSC and tumors: Homing, differentiation, and secretion influence therapeutic potential. Adv Biochem Eng Biotechnol 130: 209-266, 2012.

11. Sohni A and Verfaillie CM: Mesenchymal stem cells migration homing and tracking. Stem Cells Int 2013: 130763, 2013.
12. Rhee KJ, Lee JI and Eom YW: Mesenchymal stem cell-mediated effects of tumor support or suppression. Int J Mol Sci 16: 30015-30033, 2015.

13. Rea IM, Gibson DS, McGilligan V, McNerlan SE, Alexander HD and Ross OA: Age and age-related diseases: Role of inflammation triggers and cytokines. Front Immunol 9: 586, 2018.

14. Jammal MP, Martins-Filho A, Silveira TP, Murta EF and Nomelini RS: Cytokines and prognostic factors in epithelial ovarian cancer. Clin Med Insights Oncol 10: 71-76, 2016.

15. Zhang L, Conejo-Garcia JR, Katsaros D, Gimotty PA, Massobrio M, Regnani G, Makrigiannakis A, Gray H, Schlienger K, Liebman MN, et al: Intratumoral T cells, recurrence, and survival in epithelial ovarian cancer. N Engl J Med 348: 203-213, 2003.

16. Fong CY, Subramanian A, Biswas A, Gauthaman K, Srikanth P, Hande MP and Bongso A: Derivation efficiency, cell proliferation, freeze-thaw survival, stem-cell properties and differentiation of human Wharton's jelly stem cells. Reprod Biomed Online 21: 391-401, 2010.

17. Gauthaman K, Yee FC, Cheyyatraivendran S, Biswas A, Choolani $\mathrm{M}$ and Bongso A: Human umbilical cord Wharton's jelly stem cell (hWJSC) extracts inhibit cancer cell growth in vitro. J Cell Biochem 113: 2027-2039, 2012.

18. Gauthaman K, Abbas M, Gari M, Alsehli H, Kadam R, Alkaff M, Chaudhary A, Al-Qahtani M, Abuzenadah A, Kafienah W and Mobasheri A: Pellet culture protects bone marrow derived mesenchymal stem cells from the effects of heat shock. Front Physiol 7: 180, 2016.

19. Sturn A, Quackenbush J and Trajanoski Z: Genesis: Cluster analysis of microarray data. Bioinformatics 18: 207-208, 2002.

20. Lee HY and Hong IS: Double-edged sword of mesenchymal stem cells: Cancer-promoting versus therapeutic potential. Cancer Sci 108: 1939-1946, 2017.

21. Trompet S, de Craen AJ, Mooijaart S, Stott DJ, Ford I, Sattar N, Jukema W and Westendorp RG: High innate production capacity of proinflammatory cytokines increases risk for death from cancer: Results of the PROSPER study. Clin Cancer Res 15: 7744-7748, 2009.

22. Gocheva V, Chen X, Peters C, Reinheckel T and Joyce JA: Deletion of cathepsin $\mathrm{H}$ perturbs angiogenic switching, vascularization and growth of tumors in a mouse model of pancreatic islet cell cancer. Biol Chem 391: 937-945, 2010.

23. Dobrzycka B, Mackowiak-Matejczyk B, Terlikowska KM, Kulesza-Bronczyk B, Kinalski M and Terlikowski SJ: Serum levels of IL-6, IL-8 and CRP as prognostic factors in epithelial ovarian cancer. Eur Cytokine Netw 24: 106-113, 2013.

24. Mustea A, Könsgen D, Braicu EI, Pirvulescu C, Sun P, Sofroni D, Lichtenegger W and Sehouli J: Expression of IL-10 in patients with ovarian carcinoma. Anticancer Res 26: 1715-1718, 2006.

25. Fujisawa T, Joshi B, Nakajima A and Puri RK: A novel role of interleukin-13 receptor alpha2 in pancreatic cancer invasion and metastasis. Cancer Res 69: 8678-8685, 2009.

26. Charles KA, Kulbe H, Soper R, Escorcio-Correia M, Lawrence T, Schultheis A, Chakravarty P, Thompson RG, Kollias G, Smyth JF, et al: The tumor-promoting actions of TNF-alpha involve TNFR1 and IL-17 in ovarian cancer in mice and humans. J Clin Invest 119: 3011-3023, 2009.

27. Zhu W, Shiojima I, Ito Y, Li Z, Ikeda H, Yoshida M, Naito AT, Nishi J, Ueno H, Umezawa A, et al: IGFBP-4 is an inhibitor of canonical Wnt signalling required for cardiogenesis. Nature 454: 345-349, 2008

28. Kumar J, Fraser FW, Riley C, Ahmed N, McCulloch DR and Ward AC: Granulocyte colony-stimulating factor receptor signalling via Janus kinase 2/signal transducer and activator of transcription 3 in ovarian cancer. Br J Cancer 110: 133-145, 2014

29. Lewis AM, Varghese S, Xu H and Alexander HR: Interleukin-1 and cancer progression: The emerging role of interleukin-1 receptor antagonist as a novel therapeutic agent in cancer treatment. J Transl Med 4: 48, 2006.

30. Konishi N, Miki C, Yoshida T, Tanaka K, Toiyama Y and Kusunoki M: Interleukin-1 receptor antagonist inhibits the expression of vascular endothelial growth factor in colorectal carcinoma. Oncology 68: 138-145, 2005.

31. Owens GL, Price MJ, Cheadle EJ, Hawkins RE, Gilham DE and Edmondson RJ: Ex vivo expanded tumour-infiltrating lymphocytes from ovarian cancer patients release anti-tumour cytokines in response to autologous primary ovarian cancer cells. Cancer Immunol Immunother 67: 1519-1531, 2018.

32. Chang CJ, Chen YH, Huang KW, Cheng HW, Chan SF, Tai KF and Hwang LH: Combined GM-CSF and IL-12 gene therapy synergistically suppresses the growth of orthotopic liver tumors. Hepatology 45: 746-754, 2007. 
33. Su EW, Moore CJ, Suriano S, Johnson CB, Songalia N, Patterson A Neitzke DJ, Andrijauskaite K, Garrett-Mayer E, Mehrotra S, et al: IL-2R $\alpha$ mediates temporal regulation of IL-2 signaling and enhances immunotherapy. Sci Transl Med 7: 311ra170, 2015.

34. Broughton SE, Dhagat U,Hercus TR, Nero TL, Grimbaldeston MA Bonder CS, Lopez AF and Parker MW: The GM-CSF/IL-3/IL-5 cytokine receptor family: From ligand recognition to initiation of signaling. Immunol Rev 250: 277-302, 2012.

35. Giuntoli RL II, Webb TJ, Zoso A, Rogers O, Diaz-Montes TP, Bristow RE and Oelke M: Ovarian cancer-associated ascites demonstrates altered immune environment: Implications for antitumor immunity. Anticancer Res 29: 2875-2884, 2009.

36. Gao J, Zhao L, Wan YY and Zhu B: Mechanism of action of IL-7 and its potential applications and limitations in cancer immunotherapy. Int J Mol Sci 16: 10267-10280, 2015.

37. Green DS, Nunes AT, Annunziata CM and Zoon KC: Monocyte and interferon based therapy for the treatment of ovarian cancer. Cytokine Growth Factor Rev 29: 109-115, 2016.

38. Zsiros E, Duttagupta P, Dangaj D, Li H, Frank R, Garrabrant T, Hagemann IS, Levine BL, June $\mathrm{CH}$, Zhang L, et al: The ovarian cancer chemokine landscape is conducive to homing of vaccine-primed and $\mathrm{CD} 3 / \mathrm{CD} 28$-costimulated $\mathrm{T}$ cells prepared for adoptive therapy. Clin Cancer Res 21: 2840-2850, 2015.
39. Ding L, Li B, Zhao Y, Fu YF, Hu EL, Hu QG, Ni YH and Hou YY: Serum CCL2 and CCL3 as potential biomarkers for the diagnosis of oral squamous cell carcinoma. Tumor Biol 35: 10539-10546, 2014.

40. Bronger H, Singer J, Windmüller C, Reuning U, Zech D, Delbridge C, Dorn J, Kiechle M, Schmalfeldt B, Schmitt M and Avril S: CXCL9 and CXCL10 predict survival and are regulated by cyclooxygenase inhibition in advanced serous ovarian cancer. Br J Cancer 115: 553-563, 2016.

41. Bermudez Y, Aquino MM, Saunders BO, Coppola D, Nicosia SV and Kruk PA: Cytokines modulate telomerase activity in human ovarian cancer cell lines. AACR 64: 224, 2004.

42. Zhang C, Yang SJ, Wen Q, Zhong JF, Chen XL, Stucky A, Press MF and Zhang X: Human-derived normal mesenchymal stem/stromal cells in anticancer therapies. J Cancer 8: 85-96, 2017.

43. Gauthaman K, Fong CY, Subramanian A, Biswas A and Bongso A: ROCK inhibitor Y-27632 increases thaw-survival rates and preserves stemness and differentiation potential of human Wharton's jelly stem cells after cryopreservation. Stem Cell Rev 6: 665-676, 2010.

c) (i) $\Theta$ This work is licensed under a Creative Commons Attribution-NonCommercial-NoDerivatives 4.0 International (CC BY-NC-ND 4.0) License. 